\title{
CONTRIBUIÇÃO GEOGRÁFICA PARA O ESTUDO DO LUGAR
}

\author{
Msc. Márcio Luís Hassler \\ Mestrado em Geografia pela Universidade Federal do Paraná \\ Professor da Educação Básica da Rede Pública Estadual em Curitiba/ PR e da Rede Municipal de Araucária/PR \\ Rua José Pereira dos Anjos, No 210, Apto 32, Bloco 05, CEP: 81270-260, Curitiba (PR), Brasil \\ Tele:(41)8817-4109- malupfrs@yahoo.com.br
}

\begin{abstract}
RESUMO
Vive-se num mundo e num tempo de profundas mudanças. E neste processo de constantes transformações, modificamse também as expectativas. Não somente aquelas relacionadas ao lugar em que se vive, mas também as relacionadas ao mundo como um todo. Por isso não se pode mais pensar em um ensino de transmissão de conhecimentos. A questão agora é organizar formas de apropriação deste conhecimento, em que o sujeito seja capaz de levá-lo para sua própria vida e não apenas de ser informado com conteúdos, às vezes, fragmentados e dispersos que logo passam. E o estudo do lugar pode ser um bom exemplo para se pensar na possibilidade de um ensino contextualizado, levando em conta a forma como a sociedade vem assimilando as transformações do mundo atual.
\end{abstract}

Palavras-chave: lugar, geografia, ensino, séries iniciais.

\begin{abstract}
We live in a world and in a time of deep changes. And in this process of constant transformations, they also modify the expectations. Not only those related to the place where we live, but also the related to the world as a completely. Therefore we cannot more think about a teaching of transmission of knowledge. The subject now is to organize forms of appropriation of this knowledge, in that the subject is capable to take its for his own life and not just of being informed with contents, sometimes, fragmented and dispersed that soon pass. And the study of the place can be a good example to think in the possibility of a teaching contextualizado, taking into account the form as the society is assimilating the transformations of the present world.
\end{abstract}

Key words: place, geography, teaching, initial series

\section{RESUMEN}

Vivimos en un mundo y una época de cambios profundos. Y este proceso de cambio constante, es expectativas también cambián. No sólo las relacionadas con el lugar donde uno vive, sino también las relacionadas con el mundo como un todo. Por lo tanto, ya no podemos pensar en la enseñanza de la transferencia de conocimientos. La cuestión ahora es organizar las formas de apropiación del conocimiento, donde el sujeto es capaz de llevarlo a su propia vida y no sólo a ser informado con el contenido, as veces fragmentados y dispersos que desaparecen en seguida. Y el estudio del lugar puede ser un buen ejemplo a considerar la posibilidad de una perspectiva de la enseñanza, teniendo en cuenta la forma en que la sociedad se cambia gradualmente en el mundo de hoy.

Palabras-clave: lugar, Geografía, enseñanza, Serie Inicial.

\section{Introdução}

No decorrer da vida e em todos os momentos cada um possui um lugar. Fisicamente é o espaço que se ocupa, que se produz, que se constrói, é o território.

Por isso tem-se que entender as características que este lugar apresenta, as possibilidades e os obstáculos. Sem o conhecimento do lugar em que se está vivendo não se domina no sentido de ser sujeito consciente do que se faz, pelo contrário, corre-se o risco de ser levado, sem saber para onde nem como.

Vive-se num mundo e num tempo de profundas mudanças. E neste processo de constantes transformações, modificam-se também as expectativas. Não somente aquelas relacionadas ao lugar em que se vive, mas também as relacionadas ao mundo como um todo. Aquilo que hoje está sendo significativo, amanhã poderá não sê-lo mais. Tudo tem sido muito rápido, aquilo que é novidade agora, logo está superado porque as mudanças são muito dinâmicas.

Por isso não se pode mais pensar em um ensino de transmissão de conhecimentos. A questão agora é organizar formas de apropriação deste conhecimento, em que o sujeito seja capaz de levá-lo para sua 
própria vida e não apenas de ser informado com conteúdos, às vezes, fragmentados e dispersos que logo passam. Callai (1999) já afirma que na verdade a escola não é lugar da informação, mas sim o lugar do conhecimento.

Portanto compete aos professores desde as séries iniciais proporcionar os meios para que o aluno descubra nas práticas e no cotidiano os conhecimentos sobre o seu próprio meio, tornando-os capazes de discernir e valorizar os seus saberes, para ampliar seus conhecimentos.

E o estudo do lugar pode ser um bom exemplo para se pensar na possibilidade de um ensino contextualizado, levando em conta a forma como a sociedade vem assimilando as transformações do mundo atual. Ao construir os conceitos de espaço e de tempo, verificando a sua história de vida, vinculada com a história do lugar, o aluno começa a formular perguntas sobre como as paisagens foram criadas, que pessoas vivem ou viveram ali, como ocupam ou ocuparam aquele lugar, que atividades realizam ou realizaram. Enfim, como ocorreu este processo que lhes é visível. Através disso o aluno começa a formular seus próprios conhecimentos, relacionando os seus saberes com o conhecimento fornecido pela escola.

\section{As transformações do mundo e as mudanças no ensino}

$\mathrm{Na}$ literatura geográfica o lugar está presente de diversas formas. Estudá-lo é muito importante para o aluno, pois ao mesmo tempo em que ele é global, as relações se concretizam nos lugares específicos. Conforme Callai (2000), apoiada em Santos (1996) cada lugar é, à sua maneira, o mundo, a história concreta do nosso tempo repõe a questão do lugar numa posição central.

Então, estudar e compreender o lugar em geografia significa compreender as relações que ali ocorrem interrelacionado-as, e isso remete novamente a importância do aluno conhecer o lugar onde mora para compreender a relação entre escalas maiores do regional para o local.

O lugar está repleto de relações históricas de vínculos afetivos que ligam as pessoas aos lugares, as paisagens e tornam-se significativas ao estudo, pois compreender o meio em que vive permite ao sujeito conhecer a sua história e conseguir entender os fatos que ali aconteceram. Nenhum lugar, portanto é neutro. Pelo contrário, é repleto de histórias, com relações históricas situadas num tempo e num espaço. E que através de análises podem ser estudados e analisados para compreensão e apontamentos de possíveis alternativas.

Estudar o lugar, portanto, deve ser algo desafiante e instigante para ser tratado nas aulas de geografia, algo que desperte o aluno para a investigação do lugar e que torne o agente do processo da construção do conhecimento.

O desafio é como tornar este estudo num instrumento de construção da cidadania, fazendo com que o estudante tenha instrumentos adequados para fazer a leitura e a compreensão do espaço em que ele vive, para que, conhecendo-o, possa interagir com ele e, assim, melhor organizá-lo para poder nele viver mais dignamente.

Santos (2001) afirma que

em um mundo em que tudo está globalizado, e a informações ultrapassam fronteiras, o lugar assume contornos importantes. O processo de globalização impõe uma lógica que fragmenta os espaços para além das divisões políticas e administrativas, torna-se indispensável analisar de um modo crítico qual é o novo lugar que se atribui aos velhos lugares, pois os lugares são a reprodução, num determinado tempo e espaço, do global, do mundo (p. 37).

O meio em que se vive é o ponto de partida para estudar e analisar o espaço, é ali que ocorrem todos os fatos do dia-a-dia, é a dimensão mais próxima que o aluno conhece e, é a partir desse espaço que o aluno começa a fazer relação, pode comparar os novos lugares com os antigos, o porquê destas transformações, e decorrência de que fato atribui-se novos significados aos lugares. 
Compreender o espaço supõe conhecê-lo entendendo o seu processo de formação. E entender que deste processo todos os homens fazem parte, pois se constrói a história, construindo e modificando o espaço.

Assim, ensinar geografia tornou-se algo fundamental para se compreender o espaço. Mas o estudo da geografia só será válido ao deixar de lado esta visão ingênua e apolítica da realidade que é produtora de uma cidadania contemplativa e inerte, do tipo que em sala de aula transmitem-se informações, e depois os alunos que façam as conexões lá fora, um ensino desvinculado da realidade do aluno, que não faz a relação entre a teoria e a prática, e que não contempla os saberes que o aluno traz consigo.

Ageografia no passado buscava com este perfil o status de ciência já que na época do seu nascimento, em fins do século XVIII, o medo de ser taxada de política fez com que se buscasse sua despolitização e sua acomodação. Entretanto, as reformulações no pensamento geográfico sobre as quais já foi exposto, principalmente, um novo modo de atuar pedagogicamente, vinculando com uma práxis que transforme.

Portanto, ser educador, implica estabelecer relações entre a escola e a vida, entre sua área de estudo e outra disciplina, mostrando um mundo mais real ao aluno, ligado numa visão que deve superar as ideologias, o irreal mundo por nós construído, mudando assim este modelo ainda vigente em nossos livros didáticos da tradicional concepção da geografia, que trabalha isoladamente seus conteúdos como; a natureza (clima, vegetação, relevo); a população (dados estatísticos) e a economia (extrativismo mineral), sem estabelecer relação entre elas. Kaercher (1998) também faz uma crítica no sentido de

que este é um projeto de geografia presente décadas em nossas salas de aula e, sejamos claros, uma visão particular de ciência, a geografia iluminista - positivista, que ainda vigora até hoje no Brasil. Iluminista porque concebe o saber escolar como a luz a iluminar as trevas da ignorância. Positivista porque pretendia ser neutra, longe das polêmicas e conflitos (p. 56).

Estende-se, assim, até hoje a crença arraigada de que a geografia deve apenas descrever locais ficando presa às aparências, apresentando um currículo com uma visão bem tradicional do mundo.

Muitos livros didáticos herdaram daí o esqueleto de seus conteúdos, pois de acordo com Kaercher (1998) qualquer pessoa que passou pela escola repete quase automaticamente que a geografia é o estudo do clima, do relevo, da vegetação, da população e da economia dos lugares.

Hoje, porém, já se pode ousar mudanças. Mas para se conseguir é necessário primeiramente derrubar os mitos que muitas vezes se constrói por ignorância e deixar de lado as desculpas que muitas vezes se usa para justificar a acomodação. Algumas desculpas são bastante comuns no meio docente, tais como: 'tenho que vencer o conteúdo' ou 'a direção da escola nos obriga a seguir tal orientação' ou ainda 'temos que dar matéria para sermos considerados bons professores'.

Os professores têm que ter bem claro que a quantidade de matéria dada não vai caracterizar um bom professor, mas sim a lógica com que ele opera, ao ajudar o aluno a interpretar e compreender o que está sendo trabalhado. Normalmente trabalhar conteúdos isolados faz com que o aluno decore, não estabelecendo as relações necessárias para a assimilação do conhecimento.

Nesse contexto muitas vezes o livro texto passa a ser o senhor do processo pedagógico, ao invés de estar a serviço do professor, como mais um instrumento a enriquecer o processo de construção do conhecimento.

O professor também deve estar preparado, ter clareza sobre quais pressupostos teóricos e metodológicos, vão fundamentar o seu trabalho, pois se almejar sair do tradicional, se ousar voar mais alto, só há um caminho: estudar, pesquisar e encontrar possíveis alternativas, para tornar as aulas de geografia mais dinâmicas e atraentes ao aluno. E isso remete diante da problemática de como ensinar a geografia ou o que quer que seja, se nem os professores a conhecem claramente. Enquanto não se tiver claro os referenciais teóricos e os objetivos, não se conseguirá construir um conhecimento verdadeiro, muito menos estabelecer uma relação de ensino aprendizagem com o aluno.

É necessário, portanto, estudar, trabalhar mais em grupo, dividir e trocar experiências, e idéias com os colegas, sejam eles da mesma área ou não, participar de cursos procurando atualizar-se. 
Tanto em outras áreas como na geografia se não se for além questionando e instigando o aluno, vai se ficar sempre na mesmice, por exemplo, se o mundo em que se vive é injusto, é desigual, deve-se propor alternativas de organização do espaço, além de apenas sugerir a simples descrição ou transmitir o amontoado de informações que recaem sobre o aluno, como um enorme peso. Deve-se oportunizá-lo a entender o problema e não somente falar sobre ele, fazer com que o aluno preste atenção, vendo e analisando fatos, que até então eram insignificantes. Isso o estimulará a ver o mundo com outros olhos.

Portanto, se os professores conseguirem estimular os alunos e construírem com eles a idéia de espaço geográfico, local onde ele vive ainda, enxerga, toca, estará se trazendo a geografia para o mundo dele. Deve-se mostrar que este espaço está impregnado de sua ação, que se faz geografia no dia-a-dia, através do trabalho que é a constante na relação sociedade - natureza. Então a partir daí se terá mais chances de realizar um diálogo entre professores e alunos.

Deve-se deixar claro que o espaço não é apenas palco passivo onde os seres humanos atuam. Ele é também elemento influenciador, organizador, estimulador de ações e é por isso que se deve compreendêlo para melhor atuar sobre ele.

Dessa forma, nada acontece fora do espaço, e relacionar estes espaços com as pessoas que ali habitam e interagem é imprescindível para compreender a sociedade. Estudá-lo, portanto, é de fundamental importância, e esta parece ser umas das principais colaborações do ensino da geografia.

\section{A Importância do estudo do lugar}

O grande desafio que se apresenta ao ensino nas séries iniciais do nível fundamental é de como fazer uma geografia contextualizada que privilegie os estudos locais, especialmente a significância do conteúdo para a vida dos alunos.

O espaço resulta de um longo processo de construção da própria sociedade. As relações sociais que ocorrem num determinado espaço são mais fáceis de serem observadas e concretizadas pelo aluno, pois fazem parte do seu contexto e cabe, à geografia, fazer o estudo e a interpretação desta realidade, sem ficar preso a apenas a aparências, são necessários alguns pressupostos básicos para que possamos compreender o espaço constituído pelos homens tais como: um olhar especial sobre a realidade, a escala de analise ao observar o lugar, a natureza que está presente na análise, a paisagem que se vai observar, como ocorreu a formação do espaço, a dimensão histórica, são todos recursos que se bem explorados tornam mais atraente e interessante o estudo do lugar.

Num espaço imenso, planetário, mundial o que dele e nele estudar? Como trabalhar o local, o regional, o nacional e global.

As regras para estudá-lo, variam, podem ser gerais, universais, mas se materializam, acontecem, em lugares específicos, numa cidade, ou numa localidade, sendo que o nível local é o que traz em si o global, assim como o regional e o nacional (Callai, 1988).

E isso remete à importância do estudo do lugar, pois ele está presente de diversas formas e ao mesmo tempo em que o mundo é global, os fatos e as coisas da vida se concretizarem em lugares específicos.

Portanto, estudar o lugar em geografia significa compreender o lugar em que se vive além das condições humanas e naturais, buscando sua identidade com o lugar.

Pois nenhum lugar surge do nada, ele é o resultado da história das pessoas que ali viveram, ou vivem, de como se estabeleceram, ou estabelecem suas relações de trabalho de produção, enfim de como se manter em sociedade. É muito importante analisar os vínculos afetivos que ligam a determinados lugares, pois para a criança aquele é o único lugar conhecido, é onde ela se sente segura, ela é agente, ela sabe se localizar sabe dialogar sobre ele, pois ela o conhece é o seu lugar é o mundo em que ela vive e atua.

Deve-se ter clareza que, para obter a maior compreensão no estudo do lugar não se pode estudálo isoladamente no sentido de só se analisar os aspectos físicos e geográficos, deve-se sempre relacionálo com os aspectos históricos do lugar, pois é necessário entender a trajetória da construção do espaço, para posteriormente descrevê-lo e fundamentá-lo. 
E a Geografia é, portanto, dentre todas as ciências sociais, aquela que tem por preocupação compreender o espaço construído pelos homens. Assim, ela pode ser ensinada e vivenciada desde a préescola, se considerarmos que o espaço próprio da criança vai sendo ampliado na medida de sua socialização. A criança vai conhecendo e compreendendo o espaço a partir de si e do meio em que vive, adquirindo cada vez mais informações que a levarão a compreensão do seu lugar.

Mas, ensinar e estudar geografia não se constitui apenas em elencar dados daquilo que é aparente e observável. A geografia é a ciência que estuda a construção do espaço pelos homens, a partir da forma como estão organizadas em sociedades e das condições naturais daquele espaço, muitas vezes é justamente o que não é aparente, sendo a essência, portanto, e nem observável, necessitando ser descoberto, investigado.

Ao estudar o espaço local, se permite não só constatar, mas inclusive tornar mais complexa a organização e valorizá-lo por ser um meio próximo no qual o aluno está inserido, sendo palpável e conhecido. Então a geografia tem em sua leitura, a interpretação e na sua escrita, a representação desse espaço. O espaço geográfico em interação permanente entre a natureza e as ações humanas no seu fazer social, torna concreta as diferentes escalas de análise, do local ao global. Conforme Schaeffer (1998) a paisagem geográfica é um recorte específico que sintetiza os diversos tempos que traçam a atual fisionomia dos lugares - um foco importante para a compreensão do conceito geográfico e para a compreensão do mundo.

O estudo do lugar pode ser uma possibilidade de se fazer a relação do local do regional com o global, tornou-se um recurso de fundamental importância. Este aspecto também é reforçado nos Parâmetros Curriculares Nacionais (PCNs) e a leitura das paisagens dos lugares vem se tornando mais defendida no ensino da geografia, em obras de diversos autores que se dedicam a esse estudo. Tomando a paisagem mais próxima da escola, o bairro ou até a própria cidade, uma área a ser visitada a uma certa distância, ou uma imagem de paisagem, seja ela por foto ou outra forma representação qualquer, tem-se a base concreta para a realização da prática escolar.

Desse modo, a leitura da paisagem, no processo da aprendizagem é de suma importância para ler e compreender o mundo e o papel de cada um no mundo. Para que o aluno desenvolva a sua capacidade, a identidade com seu tempo e com seu lugar. A leitura do lugar é o recurso que permite uma série de capacidades como a observação, o registro, a produção, a análise, a compreensão e a representação que em geografia tem o seu caráter específico.

E o papel do professor é de planejar com atenção a leitura do lugar e sensibilizar o grupo para o exercício, permitindo aprofundar o trabalho realizado qualificando os resultados. $\mathrm{O}$ aluno deve ser orientado para fazer a leitura da paisagem, no sentido que o aluno consiga levantar suposições, hipóteses e pensar soluções ou alternativas diferenciadas ao que se verificou como problemática.

Portanto, a leitura do lugar é rica por que é marcada pelo movimento da criação do aluno. Ela possibilita, através da interpretação dos conceitos de Schaeffer (1998), ir paulatinamente avançando no sentido da complexificação nos estudos geográficos e da discussão de valores e atitudes do grupo em relação a um lugar: o seu lugar de vida ou no mundo, o lugar das coisas.

Cabe ao professor de Geografia aproximar-se de colegas das outras áreas, para enriquecer, com mais subsídios a sua prática, fazendo um trabalho interdisciplinar em relação ao estudo do lugar; e no caso das séries iniciais, o próprio professor articular a aproximação dos diferentes saberes.

Há várias formas de se trabalhar interdisciplinarmente, como o estudo dos Temas Transversais, onde estudar lugares, territórios, paisagens e regiões pressupõem lançar mão de uma ampla base de conhecimentos que não se restringem àqueles produzidos dentro do corpo teórico e metodológico apenas da geografia.

No ensino da Geografia, as questões sociais fazem parte de seu próprio objeto de estudo e é fundamental abordá-las em diferentes contextos de aprendizagem, tanto na própria área como no convívio escolar do aluno. 
Assim, o estudo do lugar pode ser relacionado com a ética, que trabalha o respeito mútuo, a justiça, o diálogo e a solidariedade, que aparecem traduzidos nos eixos propostos em geografia, valorizando o lugar como expressão de uma identidade, percebendo é produto de ações coletivas, podendo ser menos discriminatórios e mais hierarquizados.

Na pluralidade cultural, que valoriza o saber escolar e o universo cultural do aluno, valorizando as vivências de seu cotidiano que são fundamentais no processo de ensino aprendizagem.

$\mathrm{Na}$ orientação sexual, onde se pode situar no mesmo patamar os papéis desempenhados por homens e mulheres na construção da sociedade. Comentando sobre o preconceito existente, criando situações para que o aluno possa construir e aplicar seus conhecimentos geográficos, contribuindo para que ele compreenda a realidade e atue criticamente na sociedade.

Quanto ao meio ambiente, referindo-se às interações entre a sociedade e a natureza, um leque de temáticas referentes ao assunto se abre, podendo-se abordar a ocupação do solo, como foi feita, o crescimento populacional de determinada área, a urbanização e suas implicações. A proposta para o estudo das questões ambientais favorece uma visão clara dos problemas de ordem local, regional e global, ajudando na sua compreensão e explicação, fornecendo elementos para a tomada de decisões e permitindo intervenções necessárias.

Na saúde pode-se cruzar dados sobre o assunto com temas relativos às desigualdades regionais de distribuição de renda, abordar as relações entre o campo e a cidade, discutindo modelos agrícolas e a fome.

E ainda relacionar o trabalho e o consumo como uma das formas de expressão humana e de suas relações com a natureza, destacando as transformações ocorridas na natureza a partir da necessidade de consumo das sociedades.

Pode-se, portanto, trabalhar o espaço e o lugar de diversas maneiras, interrelacionando-as com diversos temas, tornando-o mais prazeroso e de fácil compreensão por parte do aluno.

Porém, eles devem ser trabalhados num processo evolutivo que deve ser iniciado e seguido nas primeiras etapas do processo ensino - aprendizagem do aluno. Mas tem-se que ter bem claro que, apesar das vantagens pedagógicas do estudo do lugar, pode ocorrer uma visão empobrecida do que está próximo. Isso ocorre se não forem valorizados os conhecimentos que o aluno trouxer consigo, relacionando este conhecimento com o local, o regional e o mundial, concomitante através do jogo de escalas.

Torna-se imprescindível que os professores superem este discurso concêntrico, de partindo do "eu" para mais distante, considerando equivocadamente que o mundo acontece numa seqüência linear de distância. Deve-se sim reconhecer no local as regras universais e poder pensar globalmente como todas as pessoas agem ou devem agir nos lugares. É uma leitura em que o pensamento dialético permite que se estabeleçam pontes que tornem possível a compreensão dos lugares no mundo com toda a complexidade que os caracteriza e com todas as contradições que existem.

E para que ocorra o aprendizado necessário, de acordo com as idéias de Vygotsky (1999), deve-se considerar o processo de ensino-aprendizagem, incluindo sempre aquele que aprende, aquele que ensina e a relação entre as pessoas justamente por ênfase nos processos sócio-históricos, a idéia de aprendizado inclui a interdependência dos indivíduos envolvidos no processo. Isso quer dizer que o aluno aprende no convívio com outras pessoas no cotidiano, o aprendizado não está restrito à sala de aula, que tanto o professor como o aluno, estarão envolvidos em situações de aprendizado onde o aluno trará conhecimentos empíricos contextualizados das suas vivências.

Através da compreensão dos significados do lugar e do espaço no mundo a criança passa pela aquisição de conhecimentos para sua própria localização dentro do espaço estudado, começando a interpretar o lugar e estabelecendo relações com ele.

Assim, a leitura do espaço, entendida como uma construção humana, permite que o aluno compreenda a realidade social, em que vive, que se constitui do jogo de força entre os homens, e os grupos sociais e as relações que estabelecem com o espaço e a natureza. 
Portanto, a capacidade de compreensão do que o espaço geográfico representa para um povo, para uma sociedade, passa necessariamente pelo processo de entendimento das lógicas existentes no lugar em que se vive, se mora e se trabalha. Fazer a leitura do espaço próximo, aquele que faz parte do dia-a-dia permite que se exercite esta leitura, o conhecimento e a compreensão do que está acontecendo, permitindo que o aluno se reconheça como cidadão de um determinado lugar que faz parte de um mundo maior. E aprender a fazer a leitura e a análise do espaço é construir para si, para a sua aprendizagem a noção de espaços mais amplos, mais distantes fisicamente.

Desta forma é que ela será de utilidade para a sociedade, fazendo com que cada sujeito particularizado e cada sujeito social em seu grupo consiga reconhecer o seu pertencimento ao lugar em que vive, para que, tendo a sua identidade clara consiga desenvolver a cidadania.

\section{Leitura do lugar e alfabetização geográfica}

Fazendo uma aproximação com as idéias de Paulo Freire, grande pedagogo brasileiro, pode-se dizer que a função alfabetizadora nas séries iniciais ultrapassa a leitura das letras por que deve ser articulado com a leitura do mundo, o 'casamento' com as idéias de Milton Santos, grande geógrafo brasileiro que batalhou por uma geografia da existência no mundo.

Daí que articular alfabetização e geografia é refletir sobre o homem, natureza, a sociedade (Perez, 1999).

Portanto estar alfabetizado em geografia significa entender melhor o mundo, a sociedade em que se vive. É antes de mais nada aprender a ler o mundo, mesmo que este mundo represente apenas a cidade do aluno, a partir da qual entenderá escalas maiores, a região ou o globo como um todo, é compreender o seu contexto, e aprender a localizar-se em um espaço mais amplo.

E é essa leitura de mundo que se deve entender como sendo a alfabetização geográfica, pois de acordo com as definições de Silva uma leitura que contemple todas as relações sociais e históricas presentes nele possibilita uma leitura de mundo e concretiza a relação entre o sujeito e o objetivo do processo de alfabetização geográfica.

Um dos aspectos mais importantes na alfabetização geográfica é uma leitura mais integral e ampla para chegar a uma concepção do espaço geográfico a ser construída pelo próprio aluno através de seus conhecimentos como um sujeito que faz a leitura partindo do reconhecimento das pessoas, das coisas e dos lugares da aparência e da essência dos mesmos do lugar, enfim do seu contexto.

Segundo Freire (1996) a alfabetização deve ser entendida como a relação entre o educando e o mundo que ocorra exatamente no meio social mais geral em que os educandos, transitam, e mediada, também pelo discurso oral e diz respeito a esta prática transformadora.

Portanto, o ato de conhecimento e o ato criador do processo de alfabetização geográfica têm no alfabetizando seu sujeito, pois a aprendizagem se realiza na relação do aluno como sujeito leitor e do professor como sujeito mediador, que confere atributos e competências ao aluno na leitura do seu espaço, o objeto de leitura, segundo a construção triática de Silva (1998) ajudando a construir e elaborar seus próprios conhecimentos.

Deve-se ter consciência que para mudar a concepção de mundo tem-se que ter uma postura crítica e criadora, proporcionando ao educando oportunidades e a partir do seu contexto, do 'lugar', fazer ou estabelecer a ponte de aprendizagem com o conhecimento, reconhecendo pequenos fatos que partem do seu mundo. Dessa forma ele começará a entender a leitura do mais próximo para o distante, assim como do mais distante para o próximo.

E é a partir desse ponto que se faz necessário a função alfabetizadora da geografia nas séries iniciais e a articulação da leitura da palavra com a leitura do mundo, na perspectiva da relação do homem com seu entorno, visando sua maior compreensão, exercitada pelo olhar sobre o entorno e pela expressão do que passou pelo olhar. É onde encontrará e falará sobre o homem, o movimento e o lugar, as modificações que promove, as relações que estabelece com ele, as formas com que, historicamente foi humanizando, culturalizando, geografizando o lugar. 
E o processo de alfabetização remete a criança a este mundo cheio de transformações, para que ela possa compreendê-lo, mediado pela prática transformadora desse mundo que está sempre em 'movimento' e entender que ela também faz movimento, faz história, é agente da transformação.

É preciso assim, aprender a ler e a escrever o mundo das mais variadas maneiras, compreendendo seu contexto, descobrindo a localização em espaços mais amplos, a partir da relação da linguagem e da realidade.

Em estudo sobre a alfabetização, Freire (1996) destaca que

o processo de aprendizagem e da alfabetização se realiza no movimento dinâmico entre a 'palavra', recheada de significados e o 'mundo', agente de todo esse processo, a 'palavramundo'. Concordando com as palavras destes mestres brasileiros, a criança começa a conhecer o mundo através das palavras que são carregadas de significados que nos remetem a interpretá-los, através de interpretação, descobrimos o mundo (p. 79).

O autor ainda chama a atenção para o fato de que a leitura do mundo começa pela leitura do lugar. O espaço existencial do acontecer humano.

Partindo dessa leitura e da produção de diferentes linguagens, o ensino da geografia possibilita à criança definir outros referenciais espaciais, fazendo com que ela perceba o seu entorno, não sendo o centro do processo, ao mesmo tempo em que articula a leitura da palavra pela sistematização de símbolos e pela apropriação das convenções sobre o funcionamento das linguagens.

A função alfabetizadora nas séries iniciais se traduz na manipulação de instrumentos conceituais que auxiliem a criança a construir um raciocínio geográfico para saber e pensar o espaço. Sentimentos esses que levem a criança a pertencer a um mundo natural e social, no tempo veloz ou lento, a um único e global, a uma realidade que está em permanente transformação.

\section{Considerações Finais}

$\mathrm{O}$ ato de aprender a ler e escrever deve começar com a interpretação do meio, do contexto da criança, do cotidiano, da casa, da rua; uma leitura de mundo que ela faz mesmo antes de ler a palavra, isto é, antes mesmo de ir à escola e ingressar no processo de alfabetização formal.

Freire (1996) também afirma que fazer a geografia é dialogar com o mundo, possibilitando a criança ampliar os significativos construídos, transformando sua observação em discurso, de modo que possa compreender o conjunto de movimentos que dão sentido ao mundo.

Tomando como ponto de partida o contexto do aluno, conforme interpretação que Silva (1999) faz a partir das teorias de Vygotsky (1999), segundo o qual o desenvolvimento intelectual do indivíduo não pode se conceber sem uma referência ao mundo social que está imerso de onde vir a ser, ou já ser é que faz a diferença, despertando e estimulando seu conhecimento partindo do espaço contraditório de onde ele vem independente da sua condição social, esclarecendo também que a criança não entra para a escola como uma tabula rasa, uma peça a ser esculturada. É bem precoce a construção de idéias em torno do que é e como funciona o mundo.

E como já se afirmou, a criança antes de aprender a escrever e a ler ela já sabe interpretar o mundo a seu modo, através de suas palavras, das suas vivências e as experiências do dia-a-dia e tem o seu jeito peculiar de expressá-las.

É fundamental que se tenha presente que a aprendizagem e o ensino da geografia envolvem a observação, a análise, a criticidade e principalmente a compreensão, pois o que se aprende sem compreender não é verdadeiro.

Deve-se então, proporcionar formas de oportunizar e possibilitar a leitura e a escrita da geografia, tornando nossos alunos pessoas mais atentas e críticas para entender o mundo e para 'dialogar' com ele, que é uma das formas de fazer Geografia. 


\section{Referência Bibliográfica}

CALLAI, Helena Copetti (Org.). O ensino da Geografia. Ijuí: Unijuí, 1986.

O ensino em Estudos Sociais. Ijuí: unijuí, 1991.

. Estudar o lugar para compreender o mundo. In: CASTROGIOVANNI, Antonio Carlos (Org.).

Ensino da Geografia: práticas e contextualização no cotidiano. Porto Alegre: Mediação, 2000.

CALLAI, Helena Copetti; ZARTH, Paulo. O estudo do município e o ensino de história e geografia. Ijuí: Unijuí, 1998.

FREIRE, Paulo. A importância do ato de ler em três artigos que se completam. São Paulo: Cortez, 1996.

KAERCHER, Nestor André. Ler e escrever a Geografia para dizer a sua palavra e construir o seu espaço. In: NEVES, Iara Conceição B. et al. Ler e escrever: compromisso de todas as áreas. Porto Alegre: editora da Universidade, 1998.

PEREZ, Carmem Lúcia Vidal. Ler o espaço para compreender o mundo: algumas notas sobre a função alfabetizadora da geografia. In: Ciência Geográfica - Ano V - Vol. III, No 14. Bauru.

SANTOS, Clésio. O uso dos desenhos no ensino fundamental: Imagens e conceitos. In: PONTUSHKA, Nídia Nacib; OLIVEIRA, Ariovaldo Umbelino (Org.). Geografia em perspectiva. São Paulo: Contexto, 2002.

SANTOS, Milton (Org.). Os novos rumos da Geografia Brasileira. 4 ed. São Paulo: Hucitec, 1996.

. Por uma Geografia cidadã: por uma epistemologia da existência. In: Boletim Gaúcho de Geografia $\overline{-\mathrm{AGB}}$ / POA. Passo Fundo: Ediupf, 1996.

. Por uma globalização: do pensamento único à consciência universal. 5 ed. Rio de Janeiro: Record, 2001.

SCHÄEFFER, Neiva Otero et al. Ensinar e aprender Geografia. Porto Alegre: Editora da Universidade, 1998.

. Ler a paisagem no mapa, o livro... Escrever nas linguagens da Geografia. In: NEVES, Iara Conceição B. et al. Ler e escrever: compromisso de todas as áreas. Porto Alegre: editora da Universidade, 1998.

SILVA, Ana Maria Radaelli da. Epistemologia e história da geografia como fontes para uma proposta curricular. Campinas: Unicamp, 1999.

. Esboço de uma perspectiva construtivista para o ensino da Geografia no primeiro grau. In: Espaço

Escola. Ijuí: Ed. Unijuí. № 29, 1998.

VYGOTSKI, L. S. O desenvolvimento psicológico na infância. São Paulo: Marins Editora, 1999.

Trabalho enviado em março de 2009

Trabalho aceito em agosto de 2009 